\title{
Pedicle Screw Nut Loosening: Potentially Avoidable Causes of Spine Instrumentation Failure
}

\author{
Amit Agrawal \\ Department of Neurosurgery, Narayana Medical College Hospital, Nellore, India
}

Dear Sir,

Since the first successful fusion procedures in 1911 for the Pott disease, spinal surgical fixation devices have enhanced tremendous advancements in spinal surgeries with strong evidences showing that instrumented fusion produced a higher rate of fusion [1-3]. Although the pedicle screws are routinely used for spinal fixation, these devices can be associated with complications within a group of patients, the resulted failures may not actually be device-made failures but instead surgeon-related errors [4]. A 65-year-old man was operated for traumatic D12 fractures 6 months ago. After the surgery, everything seemed to be alright until the last month when he noticed pain in the operated region which increased with strenuous activities. There was no history of bowel and bladder disturbances recorded. General and systemic examinations were unremarkable. Motor and sensory examinations were normal. His wounds healed well and he was healthy. An X-ray check indicated the loosening of the lower left screw head (Fig. 1). Thus, the patient was being scheduled for the repositioning of the screws. The wound was re-examined and the loose nut was identified and repositioned (Fig. 2). The patient is now being followed-up and doing well.

Transpedicular instrumentation provides the most biomechanically rigid restraint to spinal motions in flexion, extension and torsion through segmental spinal purchase [5]. Apart from this, the pedicle screw systems require fewer instrumented segments thus are advantageous in preserving motion segments [6]. Despite these advantages, transpedicular fixations can be associated with the risks of screw loosening, screw breakage, screw/ rod disconnection, pseudo-arthrosis, and nerve root injury which occurs in dural laceration and pedicle fracture during screw insertions $[4,6]$. Ahmed et al. [4] reported construct failures in the form of screw binding (6 cases), screw breakage (12 cases), screw/rod dislodgement (3 cases), progressive kyphosis (5 cases), disengaged screw's cup ( 2 cases), and broken rods ( 2 cases). To avoid such mechanical construct failure, it has been suggested that there should be proper applications of the rods over the screw head in a straight perpendicular angle and applications of the screw's cup in the correct mechanical manner. The use of variable-angle (poly-axial) screws can minimize the need for rod contouring thus avoiding the pre-stress load applied on the construct and reducing the early construct failure [4]. We could not identify the true occurrences and reasons for the loosening and disengagement of the screw heads. In order to avoid such a potentially preventable complication, the handling of implants is very important. When tightening the nut, with-

Received Apr 5, 2013; Revised Apr 7, 2013: Accepted Apr 17, 2013

Corresponding author: Amit Agrawal

Department of Neurosurgery, Narayana Medical College Hospital, Chinthareddypalem, Nellore-524003, Andhra Pradesh, India

Tel: +91-8096410032, Fax: +91-861-2317962, E-mail: dramitagrawal@gmail.com 
draw from adjusting the nut, and, instead, rotate counterclockwise until the screw head loosens and produces a tuck sound. Thus, the nut is tightened with no gaps between the grooves in the screw head and the ridges.
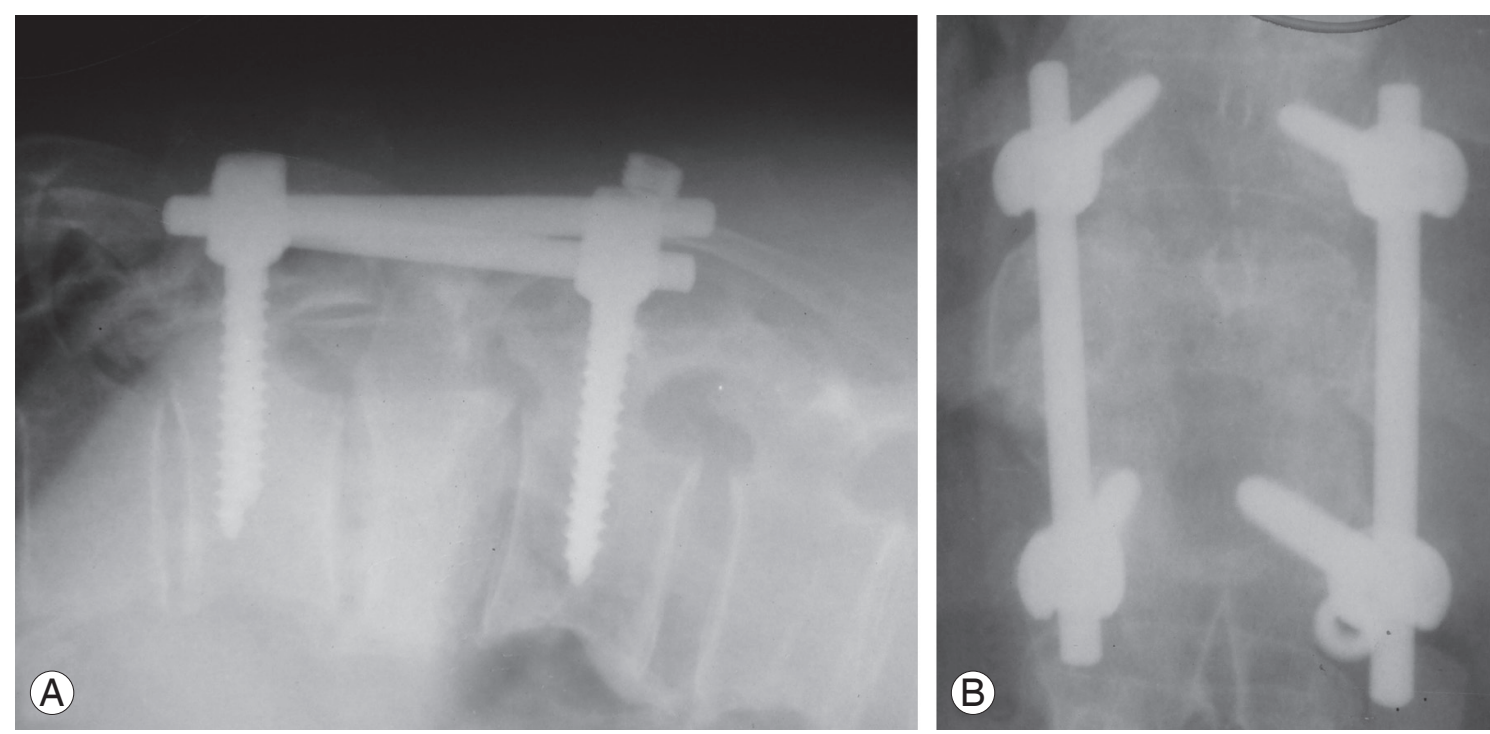

Fig. 1. X-ray dorso-lumbar spine showing asymmetry of the rods and dislodgement of the nut from screw head.
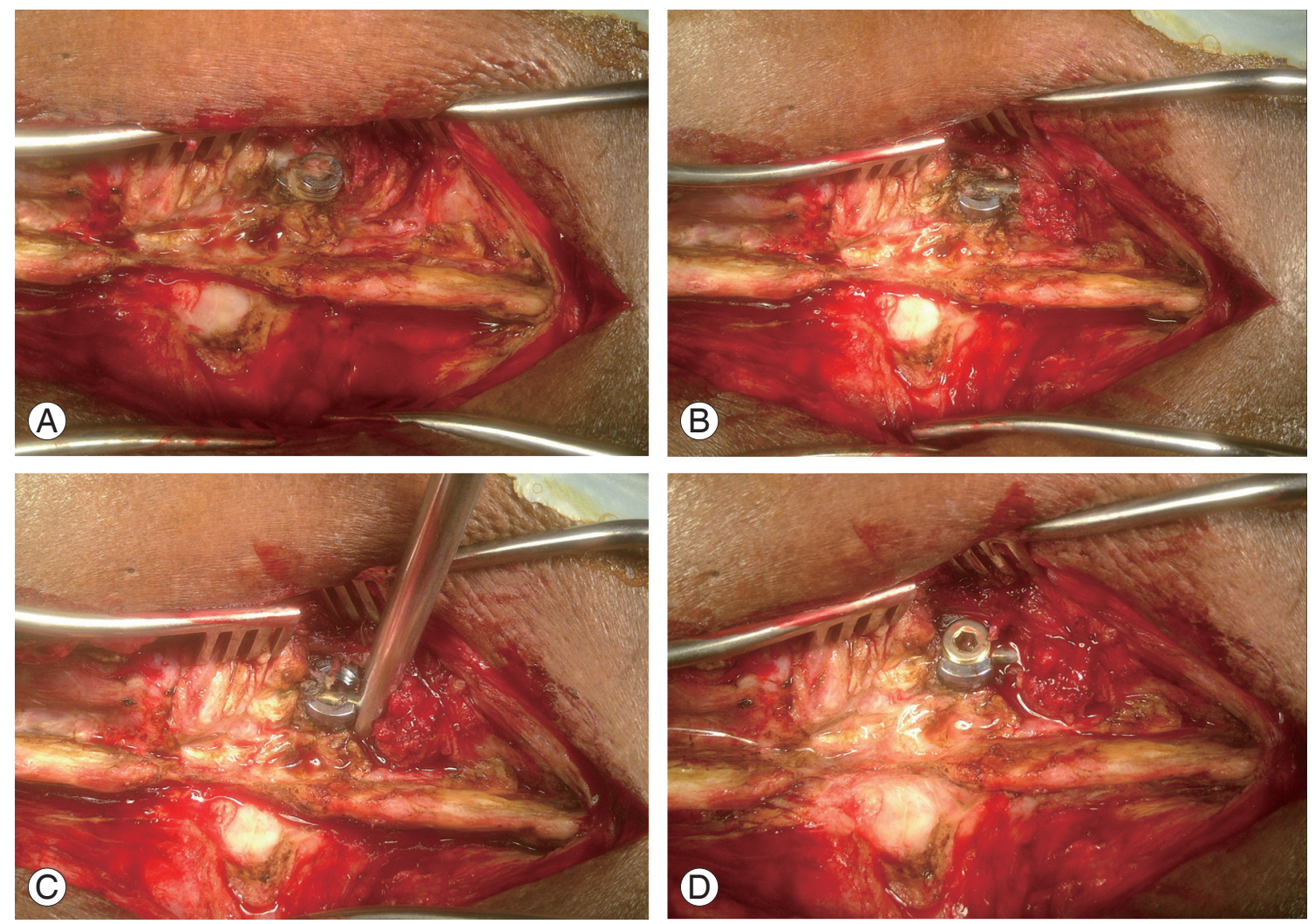

Fig. 2. (A) Intraoperative images showing loosened nut lying outside the screw head. (B) Rod in the screw head after retrieval of screw. (C) Rods being pushed down into the screw head and (D) a new nut is placed into the screw head to secure the rod in place. 


\section{Conflict of Interest}

No potential conflict of interest relevant to this article was reported.

\section{References}

1. Hibbs RA. An operation for progressive spinal deformities: a preliminary report of three cases from the service of the orthopaedic hospital. 1911. Clin Orthop Relat Res 2007;460:17-20.

2. Albee FH. Transplantation of a portion of the tibia into the spine for Pott's disease: a preliminary report
1911. Clin Orthop Relat Res 2007;460:14-6.

3. Gibson JN, Grant IC, Waddell G. The Cochrane review of surgery for lumbar disc prolapse and degenerative lumbar spondylosis. Spine (Phila Pa 1976) 1999;24:1820-32.

4. Ahmed NM, Ibrahim HB, Farg A, Sleem A. Avoidable causes in pedicle instrumentation failure. Pan Arab J Neurosurg 2011;15:29-35.

5. Trivedi JM. Spinal trauma: therapy: options and outcomes. Eur J Radiol 2002;42:127-34.

6. Davne SH, Myers DL. Complications of lumbar spinal fusion with transpedicular instrumentation. Spine (Phila Pa 1976) 1992;17:S184-9. 